\title{
OBSERVACIONES SOBRE EL PAPEL DEL TRIBUNAL CONSTITUCIONAL EN LA DELIMITACION DE COMPETENCIAS ENTRE ESTADO Y COMUNIDADES AUTONOMAS
}

\author{
POR \\ JOSE ELIZALDE \\ Universidad de Alicante
}

\begin{abstract}
SUMARIO
I. INTRODUCCión: PODER arbitral y Estado autonómico.-II. SOBre la INTERPRETACIÓN FEDERANTE DE NUESTTRA CONSTITUCIÓN.-III. ¿ES POSIBLE DEFINIR ALGUNAS CARACTERÍSTICAS COMPARADAS DEL MODELO FEDERAL DE CONTROL DE LA CONSTITUCIONALIDAD EN LA DISTRIBUCIÓN TERRITORIAL DEL PODER? -IV. SOBRE COMPETENCIAS Y CONCORDANCIAS. - V. SOBRE LA EVOLUCIÓN INICIAL DE NUESTRA JURISPRUDENCIA CONSTITUCIONAL EN MATERIA DE COMPETENCIAS TERRITORIALES.-VI. CONCLUSIONES.
\end{abstract}

\section{INTRODUCCION: PODER ARBITRAL Y ESTADO AUTONOMICO}

Si es cierto que el tema del «Tribunal Constitucional es posiblemente el tema central de nuestra Constitución» ${ }^{1}$, el corazón de ese tema central es la función arbitral del propio Tribunal en el proceso de creación del nuevo modelo territorial que supone el Estado autonómico: desde el punto de vista de la vida cotidiana individual, el amparo de las libertades sea tal vez más significativo, pero en la vida política española es con claridad ese proceso jalonado de pactos, coaliciones y paulatinas generalizaciones (como la vida política misma) el que expresa los conflictos históricos, económicos y jurídicos de mayor mag-

${ }^{1}$ García de Enterría, «La posición jurídica del Tribunal Constitucional en el sistema español: posibilidades y perspectivas», en El Tribunal Constitucional (Jornadas de estudio organizadas por la Dirección General de lo Contencioso del Estado, Madrid, Instituto de Estudios Fiscales, 1981: en lo sucesivo se abrevia esta referencia como DGCE-TC), vol. I, página 27. Este «tema central» ha merecido lógicamente una considerable atención científica por parte de la doctrina, que por otra parte este número monográfico de nuestra pionera Revista de Derecho Político aborda selectivamente. Pero sólo de pasada podemos referirnos aquí a algunos aspectos de esa documentación exponencialmente creciente, alimentada por la propia producción jurisprudencial del Tribunal Constitucional mismo. Los tres volúmenes del DGCE-TC abordaban ya el tema a conciencia, y eran anteriores al «despegue» jurisprudencial del Tribunal: en ellos se hacen, además, múltiples y meditadas referencias a lo más granado de la doctrina comparada en la materia, de Corwin, Kelsen y Schmitt, a Cappelletti, Ely o Haeberle. 
nitud y, por tanto, el que conlleva una más intensa incidencia en la labor hermenéutica de la jurisdicción constitucional.

La emergencia en nuestro régimen político de un conjunto plural de poderes arbitrales plantea quizá la muy sugestiva tarea de sintetizar y enmarcar en las tipologías comparadas esta figura del pouvoir neutre. En efecto, este «poder arbitral», encabezado - y eficazmente dirigido en su alta «función moderadora»- por la Corona (institución reveladoramente situada por la Constitución de 1978 en un papel diferenciado de su tradicional vinculación al poder ejecutivo), tiene en el Tribunal Constitucional su instrumento jurídicamente más operativo, aunque aparece también potencialmente integrado por el desarrollo constitucional y legislativo de las Administraciones públicas consultiva (desde el Consejo de Estado al nonnato Consejo de la planificación) y especialmente la de control (no obstante la vinculación formal de sus máximos exponentes orgánicos, el Tribunal de Cuentas y el Defensor del Pueblo, respecto a las Cortes Generales, no muy satisfactoria para su funcionalidad a corto plazo, pero que tiende a subrayar también en todo caso su independencia en relación con el poder ejecutivo), por no referirnos, en fin, a la práctica política de las «Comisiones de expertos» independientes que el propio Gobierno parece haber aceptado según el prestigioso modelo de las «Royal Commissions» británicas y que, por cierto, tan importante impacto están teniendo ${ }^{2}$ en la fase actual del debate político y legislativo sobre la distribución competencial entre Estado y Comunidades Autónomas.

Pero, evidentemente, ha de quedar para mejor ocasión un desarrollo de este apunte sobre el «régimen arbitral», que unas veces como corrección y otras como impulso, en definitiva, como «freno y contrapeso» (check and balance), ante la aceptada preponderancia constitucional del liderazgo del presidente del Gobierno (asimilable a su vez al Kanzlerprincip), parece configurarse como rasgo típico de nuestro actual modelo de controles políticos inter-órganos ${ }^{3}$. Baste por ahora el mero enunciado de tal enfoque para situar esta aproximación al tema crucial de la justicia constitucional: este tema podría matizarse también, desde la perspectiva histórica, utilizando aquella máxima referida al «alto Tribunal del Parlamento» en el medievo británico, subrayando los orígenes judiciales del futuro régimen parlamentario, de que «la justicia era entonces el nombre medieval de la política», como enseñara McIlwain. Justicia constitucional equivale quizá, en un desarrollo pacífico de los procesos de decisión, pero también en momentos de confusión sobre el rumbo a seguir, a política constitucional.

${ }^{2}$ Es conocida la relación entre el Informe de la Comisión de Expertos sobre Autonomias (Madrid, Centro de Estudios Constitucionales, 1981), presidida por el profesor García de Enterría y auspiciada por los dos ptincipales partidos, y la Ley Orgánica de Armonización de los Procesos Autonómicos (LOAPA).

${ }^{3}$ Son pertinentes al respecto las observaciones críticas que formula el profesor L. Martín Retortillo sobre el tradicional criterio de los «tres poderes del Estado», en relación con la cerrada enumeración del artículo 59.3 de la Ley Orgánica del Tribunal Constitucional (en lo sucesivo LOTC), respecto a los posibles órganos legitimados para suscitar conflictos de competencias (en «Conflictos constitucionales de competencia y de atribuciones», DGCE-TC, I, págs. 227 y sigs.). En cualquier caso, el quis custodet custodes podría cuestionarse de los poderes arbitrales análogamente a la desconfianza latino-germánica hacia el papel político del poder judicial. 
En este enfoque político-constitucional, la muy específica cuestión que plantearemos aquí es no tanto la verificación de una hipótesis «territorializada» sobre el papel atribuido al Tribunal Constitucional en el desarrollo de nuestro Estado autonómico, sino más bien la dificultad de definir claramente esa misma hipótesis, tanto en perspectiva comparada como contrastada singularmente con la jurisprudencia inicial en torno a conflictos de competencia y recursos de inconstitucionalidad con trasfondo territorializado ${ }^{4}$. Es decir, el problema no es ya que la función arbitral de nuestro Tribunal Constitucional sea territorialmente «federalista» o bien «unitario-regionalizadora» o un híbrido de ambos modelos, sino la muy dudosa posibilidad de definir criterios territorializados de control de la constitucionalidad más allá de la obvia constatación inicial de una convergencia histórica entre Estado federal y control constitucional.

Ahora bien: precisamente esa dificultad empírica, esa ambigüedad que resulta del análisis en una primera aproximación a los datos existentes, nos lleva a propugnar (en la referida óptica de política constitucional con que identificamos el papel de la jurisdicción constitucional como integrante de los «poderes de contrapeso» que, con mucha más efectividad que la oposición parlamentaria, vienen moderando la preponderancia de nuestro actual «régimen del presidente del Gobierno») la utilidad de una interpretación «federante» acerca de la dinámica de nuestro modelo constitucional de distribución territorial del poder: utilidad, a nuestro juicio, tanto para la estabilidad del sistema político en general como para la propia eficacia funcional del Tribunal Constitucional como instancia arbitral.

\section{SOBRE LA INTERPRETACION FEDERANTE DE NUESTRA CONSTITUCION}

Al plantearse el intento (ni siquiera la formulación) de este tipo de hipótesis territoriales sobre la función del Tribunal Constitucional en la distribución competencial entre Estado y Comunidades Autónomas se parte aquí, ciertamente, de una discutible pero, a nuestro entender, coherente interpretación de la dinámica autonómica de la Constitución española, en el sentido de su no por implícito menos efectivo carácter federante. Aunque no cabe tampoco ahora extenderse sobre esta compleja y agónica tarea de definir cuál sea el jurídico sexo de nuestras autonomías territoriales, parece imprescindible apuntar al menos esquemáticamente algunas de las razones que llevan a este abordar el tema desde una perspectiva federativa ${ }^{5}$.

4 Tampoco cabe, quizá, extrapolar excesivamente la moderada heterodoxia de esta primera aproximación. Como señala Elizalde y Aymerich, hay que evitar «la márcada tendencia a la dogmatización de los criterios jurisprudenciales (...) cuyo riesgo se acrecienta con la preeminencia attibuida al Tribunal Constitucional», El Tribunal Constitucional y la jurisprudencia, DGCE-TC, I, pág. 899. Pero sobre el tema se vuelve después.

5 Recientemente se argumenta matizadamente el «rechazo del federalismo» por el pro: fesor J. J. Solozábal, buen conocedor del tema comparativamente, en sü trabajo: «Sobre el modelo de organización territorial del Estado según la Constitución de 1978», en el númeto 13 (1982) de esta misma revista, págs. 53 y sigs., en especial págs. $55-60$, donde se reconoce en todo caso la superioridad organizativa $y$, por tanto, como técnica jurídica del tmo- 
En efecto, la raíz de la cuestión se encuentra en saber hasta qué punto el modelo de «Estado autonómico» que ha abierto - más que configurado definitivamente- nuestra Constitución de 1978 se identifica con el tipo de Estado unitario, en su variante regionalizable, o bien sus rasgos territorialmente diferenciales son más asimilables (no plenamente, como la propia indefinición constitucional del tema hace obvio, pero por ello mismo la tarea interpretativa deviene esencial) al tipo de Estado federal. Sin examinar a fondo las razones del sector de la doctrina que considera que el llamado Estado autonómico tiene en nuestro régimen constitucional una «dinámica federante», la cual sobrepasa con mucho el tipo mixto de «Estado regional» o el llamado «unitario descentralizado», y se asemeja con tendencia creciente al tipo de Estado federal ${ }^{6}$, nos limitaremos a señalar por nuestra parte:

1. La existencia de nacionalidades (concepto histórico, pero no cerrado), y no sólo de «regiones» con derecho a autonomía según el artículo 2, es compatible con una unidad nacional federalmente estructurada (así, Argentina vincula constitucionalmente la unidad nacional al federalismo, mientras que, en cam-

delo federal, en base a los valores de claridad e integración. A mi modesto entender no son plenamente convincentes sus razones para el referido «rechazo», puesto que la cláusula residual en favor del Estado, como el profesor Solozábal sin duda conoce, existe en la distribución de competencias de varios sistemas políticos federales, como son los de Canadá, India o Venezuela; en cuanto a la ausencia de rasgos paccionados y de homogeneidad generalizada en nuestros procesos autonómicos, son temas debatidos: parece indiscutible históricamente la trayectoria negociada que llevó a las autonomías catalana, vasca, gallega, andaluza o valenciana, por suficientes ejemplos; y la argumentación con que el principal partido de la oposición defiende sus propios «pactos» de 31 de julio de 1981 que sirven de trasfondo a la LOAPA se ha fundamentado, según su ideología conocidamente federalista, en el debate parlamentario sobre dicho Proyecto de ley, con razones precisamente de generalidad y bomogeneidad (por otra parte, una cláusula similar al famoso artículo $4 .^{\circ}$ de la LOAPA existe en el artículo 72 de la Ley Fundamental de la República Federal de Alemania, la «Bedürfwisklausel» o cláusula de necesidad cualificada en favor de los poderes centrales, cuando estén en juego los intereses generales: el profesor Lojendio, a quien debo esta obsrvación, ha argumentado suficientemente el grado de consenso previo en que se basan nuestras autonomías). Las diferencias de ritmo no son diferencias de naturaleza. $\mathrm{E}$ incluso la distinción entre "nacionalidades» y «regiones», de base histótica, no se articula claramente en el título VIII.

- Para una argumentación detallada y amplias referencias bibliográficas, véanse mis trabajos «Razones para una reforma federal del Título VIII de la Constitución» (Ponencia al I Congreso de la Asociación Española de Ciencia Política), Barcelona, 1980, publicado por la Junta de Andalucía en el volumen IV de las I Jornadas de Estudios Socioeconómicos de las Comunidades Autónomas, Universidad de Sevilla, 1981, págs. 45-88, y La Administración territorial en el actual régimen constitucional (Notas críticas ante la autonomia en Extremadura), Cáceres, Universidad de Extremadura, 1981, especialmente, págs. 59-62 para mi conclusión de que tenemos una «Constitución prefederal». Asimismo, De Simón Tobalina, El Estado autonómico y sus matices federales, Madrid, IEAL, 1981 (en especial, páginas 179 y sigs.); el profesor Trujillo acuñó el término de «Estado federo-regional» (en la compilación Federalismo y regionalismo, Madrid, CEC, 1979, págs. 15 y sigs.); González Casanova (Teoría del Estado y Derecho Constitucional, Barcelona, Vicens Vives, 1980, página 537) afirma el «carácter federante» de este Estado. Hasta en el amplio sector «regionalista» de la doctrina (así, Guaita, «Las regiones en la Constitución española de 1978», en Revista Internacional de Ciencias Administrativas, 1979, págs. 148 y sigs.) se admite el término de «federación imperfecta o incompleta». La propia doctrina italiana, significativamente, ha constatado las diferencias irreductibles con el postulado «regional», y ha denominado «Estado federalizable» al nuevo modelo territorial de nuestra Constitución: cfr. L. Vandelli, L'ordinamento regionale Spagnolo, Milán, Giuffré, 1980, pág. 398. 
bio, la República Popular China reconoce su carácter multinacional en un tipo de Estado unitario, es decir, federalismo y multinacionalismo son problemas distintos, pero en todo caso no «reconducibles» a lo «regional»), y son altamente significativas al respecto las formulaciones de los artículos iniciales de los Estatutos vasco y catalán, y especialmente el preámbulo de este último, cuyo valor interpretativo, si no normativo, ha reconocido el propio Tribunal Constitucional (STC de 12 de noviembre de 1981).

2. Los Estatutos autonómicos iniciados por la vía del artículo 151, como subraya especialmente la intervención directa del pueblo de la Comunidad afectada, tienen rasgos paccionados, sobre todo en los territorios forales históricos: en este sentido Legaz afirmó que la posibilidad de una «ley paccionada» para la actualización de los derechos históricos de los territorios forales, abierta en la disposición adicional primera de la Constitución (y reiterada en la disposición adicional del Estatuto vasco), «implica una idea de federalización del Estado que es la que realmente subyace en el capítulo III del título VIII sobre la organización territorial» ${ }^{7}$.

3. Es evidente el carácter básicamente dispositivo que da la Constitución a la autoorganización institucional interna, destacando políticamente además sus facultades no sólo legislativas propias, sino también de iniciativa legislativa estatal y especialmente de iniciativa en la reforma constitucional (titularidad que, en cambio, no alcanza en nuestra Constitución ni siquiera la iniciativa legislativa popular), punto este, junto a la representación propia de las Comunidades Autónomas en el Senado, aun con las insuficiencias señalables en el artículo $69^{8}$, de tipo nodal en las definiciones tradicionales más acreditadas de la especificidad del federalismo ${ }^{9}$.

${ }^{7}$ Legaz Lacambra, «Prólogo» a Starck, El concepto de ley en la Constitución alemana, Madrid, CEC, 1979, pág. 28; Castro Somoza («Las leyes de las Comunidades Autónomas en las Constituciones españolas de 1931 y de 1978», en DGCE, La Constitución española y las fuentes del Derecho, Madrid, 1980, I, págs. 465 y sigs.) considera en efecto los Estatutos de Autonomía como «leyes paccionadas». Más matizadamente, y sólo respecto a las Comunidades Autónomas «de régimen especial», admite este carácter paccionado Entrena (en Garrido Falla et al., Comentarios a la Constitución, Madrid, Cívitas, 1980, págs. 1588 1590).

${ }_{3}^{8}$ Véase mi trabajo «El Senado como Cámara de representación territorial en el Estado autonómico: una perspectiva comparada», en Revista de Política Comparada, 6, 1981, páginas 195-214.

- García Pelayo, en su trabajoso y admirable esfuerzo por especificar las características del Estado federal, frente a la teoría del «continuum» kelseniano, según la cual no existen más que grados de un proceso de centralización y descentralización («sin solución de continuidad», relativizando los viejos conceptos de Estado unitario y Estado federal), considera precisamente como uno de los dos ejes básicos el que «los Estados miembros participan en la formación de la voluntad de la Federación a través de la Cámara Federal y de su intervención en la reforma de la Constitución» ( «Derecho Constitucional Comparado», en Revista de Occidente, Madrid, 1959, 5.2 ed., pág. 244). Sigue en esto el criterio de Moushkeli, Teoría jurídica del Estado federal, Madrid, 1931, pág. 319. Habría que matizar, obviamente, que la intervención de las Comunidades Autónomas en la reforma constitucional es dispositiva en nuestro texto de 1978 - salva la participación más limitada a través del Senado-, y no preceptiva. Pero en cuanto al otro eje básico que subrayaban Moushkeli y García Pelayo, el de la «autonomía constitucional», es aún más discutido: cfr., entre otros, H. Heller (Die Souveranität, Berlín, 1927, págs. 110 y sigs.), para el que sólo el Estado federal es soberano, ya que el Estado federado «no tiene autonomía constitucional, ya que la estructura de su constitución está condicionada»; tal sería el caso, ciertamente, de nuestros Estatutos de autonomía. 
4. La legitimación autonómica para el recurso de inconstitucionalidad en el artículo 162.1.a del texto constitucional (y el discutido desarrollo de la materia de conflictos constitucionales prevista en el artículo 161.1.c en los artículos 60 y siguientes de la LOTC) suponen una relativa reciprocidad en el sistema de controles estato-comunitario, no obstante la superioridad de instrumentos en favor del Estado respecto a las disposiciones no normativas autonómicas. Este sistema responde, en suma, a una nueva situación de pluralismo normativo, puesto que, pese a la unidad formal del Estado y del ordenamiento, la Constitución consagra una diversidad de centros de producción jurídica no subordinados a la ley estatal, sino directamente derivados de la Constitución y amparados en el principio de autonomía y en la participación popular en los procedimientos de constitución y reforma estatutaria de las Comunidades Autónomas «plenas» (vía del art. 151), todo lo cual ha obligado, como es sabido y el Tribunal Constitucional ha reconocido, a situar, junto al principio de jerarquía normativa y la prevalencia de la ley estatal, al principio de distribución territorial de la competencia, y en este sentido responde al sistema kelseniano de control constitucional concentrado según una lógica federal.

5. Las amplias posibilidades de autonomía financiera abiertas por los artículos 156 a 158 descentralizan no sólo el gasto público, sino también los ingresos, lo que en casos como los conciertos con la Comunidad Autónoma del País Vasco superan en este aspecto incluso el modelo federal ${ }^{10}$; análogamente, la decisiva participación autonómica en la planificación de la actividad económica prevista en el artículo 131, y, en general, la previsión básicamente descentralizadora de la función pública.

6. La tendencia creciente a la asunción de competencias públicas por las Comunidades Autónomas, favorecida por la cláusula de indeterminación dispositiva del artículo 149.3 ( «las materias no atribuidas expresamente al Estado por esta Constitución podrán corresponder a las Comunidades Autónomas, en virtud de sus respectivos Estatutos»), alcanza, por ejemplo, en el artículo 10 del Estatuto vasco cotas singulares de «competencia exclusiva» respecto a materias no enumeradas en el artículo 148 de la Constitución, como son: cooperativas; cofradías de pescadores; cámaras agrarias, de la propiedad, de comercio, industria y navegación; colegios profesionales; sector público propio; bolsas de comercio; cajas de ahorro e instituciones de crédito corporativo, público y territorial; defensa del consumidor; desarrollo comunitario; política infantil, juvenil y de la tercera edad; espectáculos, etc. Esta tendencia entrópica de las competencias autonómicas, no obstante los principios también enunciados en dicho párrafo tercero del artículo 149 (cláusula residual a favor del poder central, así como prevalencia del derecho estatal sobre el autonómico, aun con la importante salvedad de que tal prevalencia no existe «en todo lo que esté atribuido a la exclusiva competencia de éstas», planteando, pues, la difícil

10 Véanse las referencias históricas recopiladas por A. Pedrós, La financiación de las Comunidades Autónomas en España, Madrid, IEE, 1979, y especialmente los estudios del equipo dirigido por $\mathrm{E}$. García de Enterría, La distribución de las competencias económicas entre el poder central y las autonomías territoriales en el Derecbo Comparado y en la Constitución española, Madrid, IEE, 1980, por cierto favorable a una lectura federante de nuestro título VIII. 
delimitación de la «exclusividad» autonómica), se ve reforzada además por la posible ampliación quinquenal (art. 148.2) de competencias estatutarias a costa de las teóricamente «exclusivas del Estado» del artículo 149 (ya que la propia ambigüedad de la «técnica consensual» de los «sin perjuicio de» en dicho artículo 149 relativiza así la teórica exclusividad de muchas competencias estatales), y muy especialmente por las formas de delegación legislativa y de transferencias de facultades asimismo previstas en el artículo 150 de la Constitución, hasta tal punto que la referida Comisión de Expertos advierte con alarma la «dinámica equívoca» de «expansión de las supuestas competencias exclusivas de las Comunidades Autónomas», oponiéndose «radicalmente» a estas «interpretaciones constitucionales que pueden llevar al bloqueo del sistema» ${ }^{11}$.

Sin entrar aquí en el tema de la LOAPA, directamente derivado de ese tipo de advertencias, y aunque volveremos brevemente sobre esta distribución de competencias entre poder central y autonomías territoriales, sí cabe señalar que nos encontramos, en efecto, muy lejos de una «descentralización regional» a la italiana, y en muchos aspectos más allá de las recientes tendencias centrípetas del llamado «federalismo cooperativo» indio o centroeuropeo.

7. El número y densidad de las entidades territoriales previsibles en nuestro Estado autonómico cumple plenamente las «leyes sociológicas» atribuidas por el estudio comparado de Blondel a los Estados federales, los cuales «tienen dieciséis unidades por término medio» (el número aproximadamente probable de nuestras Comunidades Autónomas), mientras que los Estados unitarios sobrepasan siempre la veintena de subunidades territoriales, sin que sus respectivos promedios demográficos superen el millón por subunidad territorial, que se acerca, en cambio, a los cinco millones en el caso de los Estados fe. derados ${ }^{12}$.

El carácter no jurídico de esta última razón ilumina, por otra parte, las limitaciones de una interpretación excesivamente formalista del texto constitucional; situándonos en una perspectiva no estática, sino dinámica y pragmática, como corresponde a esta materia de los procesos autonómicos, parece perfectamente factible relativizar las interpretaciones unitarias de nuestro «Estado autonómico», y sustentar interpretaciones federantes, reconociendo en las potestades legislativas ramificadas y en el pluralismo jurídico consiguiente, así como en los procedimientos de modificación, reforma y ampliación de varios estatutos autonómicos, en sus previsiones sobre las relaciones internacionales (que se acrecentarán con la entrada de España en las Comunidades europeas) y en su propio rango «cuasi constitucional», aspectos asimilables a una situación de «soberanía compartida». En tal perspectiva, la unidad de España es la unidad del sistema político y de la realidad histórica de la nación española, que el Estado garantiza según los principios constitucionales de igualdad, solidaridad, libre circulación, etc., pero no es ya la forma de organización territorial de tal sistema político, cuya pluralidad histórica, reconocida a través de las autonomías, adquiere rasgos semifederales (o de «federalismo cooperativo») de pluralismo normativo, todo lo cual requiere a su vez inexcusable-

11 Informe de la Comisión de Expertos, cit., págs. 35-37.

$12 \mathrm{~J}$. Blondel, «Introducción al estudio comparativo de los Gobiernos», en Revista de Occidente, Madrid, 1972, pág. 344. 
mente un escalonamiento de los órganos jurisdiccionales para el Derecho propio de cada territorio, sin perjuicio de la jurisdicción única del Tribunal Supremo (y de la del Tribunal Constitucional) para la unificación jurisprudencial y la efectividad de los principios del Estado social y democrático de Derecho que la Constitución garantiza y manteniendo un carácter supletorio (con primacía en casos de conflicto) del Derecho estatal, todo lo cual caracteriza precisamente a los Estados federales.

Un esbozo de la apoyatura tradicional de esta tesis federalista en la historia de España es ya tema que nos llevaría muy lejos. Pero baste reseñar ahora, en el propio texto de la Constitución española de 1978, la derogación expresa de la legislación antiforalista y centralizadora de 1839 y 1876, el reconocimiento de «los derechos históricos de los territorios forales» (disposición adicional primera, que ampara además su «actualización general» mediante los Derechos autonómicos), el respeto a las especialidades forales respecto a las fuentes del Derecho (art. 149.1.8.), a «los tribunales consuetudinarios y tradicionales» (art. 125), etc., por no referirnos ahora a la disposición adicional del Estatuto vasco que reivindica derechos del pueblo vasco «en virtud de su historia». Si el eje del concepto federal es la idea de pacto (foedus) ${ }^{13}$, creemos que la realidad efectiva en que cabe situar la interpretación de los aspectos territorialmente conflictivos de nuestro texto constitucional es, en nuestro sistema político vigente, un proceso de descentralización paccionada y diversificada por razones más históricas que propiamente jurídicas, configurando así un «prefederalismo» sui generis.

\section{III. ¿ES POSIBLE DEFINIR ALGUNAS CARACTERISTICAS COMPARADAS DEL DERECHO FEDERAL DE CONTROL DE LA CONSTITUCIONALIDAD EN LA DISTRIBUCION TERRITORIAL DEL PODER?}

Las diferenciaciones doctrinales más habituales sobre los modelos de control de la constitucionalidad - por otra parte, inexistente en sistemas políticos tan establemente democráticos como los nórdicos, salvo la tendencia reciente en Noruega a adoptar el modelo de «control difuso» ${ }^{14}$-, y dejando a un lado además los sistemas llamados «embrionarios» ${ }^{15}$ (por no confiar la protección

${ }^{13}$ Sin remontarnos al «principio federativo» proudhoniano, y a sus ecos de federalismo social antes que político en nuestro Pi y Margall (puede verse el documentado estudio de Trujillo, El federalismo en España, Madrid, Edicusa, 1967), tenemos una formulación lógica $\mathrm{y}$ estricta del «principio federal» como contractualismo en el mundo actual, en K. C. Wheare, Federal Government, OUP, 1963, págs. 1-14.

${ }_{14}$ Hoy día es cierto lo que señala Marcic, Verfassung und Verfassungsgericht, Colonia, Springer, 1963, págs. 80-85, de que ningún Estado quiere aparecer sin control de la constitucionalidad. De Vega ( Jurisdicción constitucional y crisis de la Constitución», en $R e$ vista de Estudios Políticos, 7, n. e., 1979, pág. 95) ha criticado el carácter semántico de muchos de estos llamados «sistemas de justicia constitucional», entre los que podría incluirse, por supuesto, el recurso de contrafuero introducido por la Ley Orgánica del Estado en el anterior régimen español.

is Artículo 277 de la Constitución de 1976, aunque ésta admite también, en su artículo 282 , el control judicial de la constitucionalidad, que se remite a la Comisión Constitucional dependiente del Consejo: cfr. referencias de Gonzalo en Boletín de Jurisprudencia Constitucional, 8, 1981, págs. 630-640. 
jurídica de la Constitución a órganos independientes, sino de carácter total o parcialmente político, en distintas versiones que van desde el Consejo de la Revolución portuguesa al Presidium del Soviet Supremo de la URSS ${ }^{16}$, pasando por el Consejo Constitucional de la V República francesa) ${ }^{17}$, suelen basarse ya en el criterio organizativo/estructural (así, control jurisdiccional difuso cuando, según el modelo norteamericano, se atribuye al poder judicial ordinario dicho control de constitucionalidad, o bien sistema de control concentrado, según el modelo inspirado por Hans Kelsen, cuando se atribuyen las garantías constitucionales a un tribunal ad boc) ${ }^{18}$, ya en el criterio procedimental/ funcional (diferenciación en este caso entre vía de acción o principal para la declaración de inconstitucionalidad, asociada con el modelo austríaco, y vía de excepción o incidental, típica de la tradición norteamericana) ${ }^{\mathbf{1}}$.

El referido esquema clasificatorio es asimismo doctrinalmente utilizado hoy para subrayar las excelencias del sistema español como «modelo mixto» en que, junto al recurso «principal» sobre la constitucionalidad de las leyes

${ }^{16}$ Frente a la desconfianza matxista-leninista (enraizada en la dogmática revolucionaria jacobina), hacia la posibilidad misma de un control judicial de la constitucionalidad de las leyes, la única importante excepción que ha compatibilizado un sistema socialista con una institución de justicia constitucional en sentido propio.es precisamente la yugoslava, que, como reconoce el propio García de Enterría (op. cit., en n. 1, supra, pág. 65, n.), está «determinada especialmente por la temática federal más que por la de principios materiales». Habría que citar también, en un tono menor, el restablecimiento en Checoslovaquia, significativamente en 1968, con las leyes constitucionales que implantan el Estado federal, del Tribunal Constitucional que había adoptado inicialmente la Constitución checoslovaca de 1920, inspirándose en el modelo austríaco-kelseniano que entró ese mismo año en funciones. Dicho Tribunal checoslovaco alcanzó algún prestigio entre 1920 y 1938, según nos recuerda, en relación comparativa con el Tribunal de Garantías Constitucionales de nuestra II República, la interesante ponencia del profesor Cruz Villalón al II Congreso de la Asociación Española de Ciencia Política (Sevilla, octubre 1981).

${ }_{17}$ Este es, quizás, el que más ha evolucionado hacia un control jurisdiccional: cfr. el número monográfico de Pouvoirs, 13, 1980, «Le Conseil Constitutionnel», especialmente los trabajos de J. Rivero y M. Waline. Su jurisprudencia es recogida por ello en el referido Boletín de Jurisprudencia Constitucional que desde 1981 edita el Servicio de Estudios de nuestras Cortes Generales.

${ }_{18}$ Existen también, como es sabido, sistemas organizativos híbridos, destacadamente el suizo, donde la competencia en materia de garantías constitucionales tiene su sede en el Tribunal Supremo Federal helvético, así como el mejicano, donde tanto el amparo frente a violaciones de garantías individuales como los conflictos entre Estados federados y la autoridad federal culminan en la Suprema Corte de Justicia. Lo más significativo en todo caso es esta asociación de los diversos modelos con el tipo de Estado federal, porque indica que el federalismo es compatible con una diversidad muy grande de sistemas (así, en el suizo, el control es muy limitado respecto a disposiciones normativas federales y amplio para las cantonales, aunque las principales atribuciones del Bundesgericht en materia constitucional son la protección de derechos individuales y los conflictos de competencia), pero que por su propia naturaleza, por su propia estructura de poder territorialmente compartido y diversificado, parece exigir la existencia de una jurisdicción constitucional arbitral y unificadora.

${ }_{19}$ Nuestra bibliografía reciente (por no referirnos a doctrina extranjera, que está recogiendo por países el citado BJC) cuenta sobre todo con los tres volúmenes citados de DGCE-TC, así como el núm. 7 (n. e. 1979) de la Revista de Estudios Políticos, monográfico sobre «garantías constitucionales», y las introducciones que han aportado ya nuestros procesalistas, como González Deleito (T'ribunales Constitucionales, Madrid, Tecnos, 1980); Almagro (Justicia Constitucional, Madrid, Distr. Dykinson, 1980), o González Pérez (Derecho Procesal Constitucional, Madrid, Cívitas, 1980), todos los cuales recogen abundantẹs aportaciones comparadas. 
(y además de otras competencias del Tribunal Constitucional, como los conflictos constitucionales o los recursos de amparo para protección de derechos fundamentales), se admiten amplias posibilidades de la llamada cuestión «difusa» de constitucionalidad, de manera que se ha plasmado, por su ámbito competencial, «la justicia constitucional más amplia que existe sobre la tierra» ${ }^{20}$.

Es curioso, sin embargo, pese a la significativa asociación ya señalada (o quizá precisamente por ello), que no suela considerarse como criterio clasificatorio útil respecto a los modelos de control de la constitucionalidad el de distribución territorial del poder: en efecto, prima facie, encontramos que sistemas políticos federales aparecen asociados tanto con el modelo difuso - los Estados Unidos- como con el concentrado - Austria o la República Federal Alemana-, y asimismo con sistemas mixtos - Suiza, México-o también con el llamado modelo "embrionario» -así, la URSS-, y por lo que parece explicable que la actual investigación comparada no haya encontrado correlaciones significativas entre ambas variables, garantías constitucionales y federalismo, pese a que hace ya un siglo (en la caracterización de Dicey sobre la revisión judicial como elemento propio del Estado federal) que está doctrinalmente señalada tal conexión.

No obstante, creo útil insistir en primer lugar en el hecho de que sea precisamente en sistemas políticos de carácter federal donde va a madurar este importante mecanismo del control de la constitucionalidad de las normas: así, es sabido que antes de la célebre sentencia del juez Marshall en el caso Marbury v. Madison de 1803 , que consagra a nivel federal la doctrina del control judicial de la constitucionalidad legislativa, existía ya una jurisprudencia inicial en los Tribunales de varios Estados norteamericanos, como Pensilvania, Vermont, Nueva York o Virginia, que establecieron así el principio de judicial review sobre la constitucionalidad de las leyes en dichos Estados miembros de la Unión ${ }^{21}$ y así pudo imponerse esta tradición al ambiguo silencio de la Constitución filadelfiana sobre el control judicial, que en realidad no carecía de antecedentes ingleses, singularmente en la doctrina de Coke, pero que sólo en un sistema federal pudo, por tanto, fructificar. Tampoco es casual que sea en una Constitución federal, la austríaca de 1920, donde se rompa en el ámbito europeo, a través de la obra de Kelsen y de su modelo innovador de «jurisdicción concentrada», la desconfianza del Viejo Continente, enraizada en las viejas fórmulas de Montesquieu sobre la «boca de la ley», hacia toda extralimitación del estricto papel interpretativo de los jueces. Es cierto que Estados unitarios (llamativamente descentralizados, como el «Estado integral» de nuestra II República o el «Estado regional» de la República italiana, y, por tanto, con conflictos territoriales de distribución del poder) desarrollan des-

20 Esta rotunda fórmula de Zweigert, referida al sistema federal alemán en el Coloquio Internacional de Heidelberg de 1961 sobre justicia constitucional comparada, es reivindicada para nuestro Tribunal Constitucional por el profesor García de Enterría, op. cit., páginas 38 y sigs. Si se siguieran las razonadas indicaciones de Rodríguez Oliver (en el volumen III de DGCE-TC, págs. 2290-2360) para ampliar la lista de materias potencialmente cognoscibles por el Tribunal, la rotundidad de la fórmula no estaría en absoluto exagerada para el caso español. Por cierto, gue esa fusión o «mixtura» tan alabada de control difuso y concentrado aparece ya en la reforma de la Constitución austríaca en 1929.

${ }^{21}$ Referencias en E. S. Corwin, The doctrine of judicial review, Gloucester, Mass., 1963, páginas 71 y sigs. 
pués esta innovación kelseniana. Tampoco los tipos sui generis ya señalados de control previo y semipolítico (modelo embrionario, como el Conseil Constitutionnel francés) alcanzan a contrapesar, pues, esta asociación básica entre federalismo y control de la constitucionalidad.

En segundo lugar, nos encontramos, sin embargo, con un hecho de significación contraria al anterior: los conflictos constitucionales y el control de constitucionalidad de las normas, los dos ámbitos más territorialmente característicos del Tribunal Constitucional, tienen garantizada una adecuada regulación tanto en diversos sistemas federales como en otros unitarios, pero regionalmente descentralizados (cuyo paradigma es desde 1947 el artículo 134 de la Constitución italiana), y entre ambos existen, por cierto, notables similitudes ${ }^{22}$.

Son justamente estas convergencias lo que vamos a explorar aquí en relación con el papel del Tribunal Constitucional en nuestro ambiguo «Estado autonómico».

Centrándonos en los dos modelos de jurisdicción constitucional que más directamente han influido en nuestra institución de control: a) el federal alemán, con su Bundesverfassungsgericbt regulado por la Ley de 7 de febrero de 1971 (modificada en 1974 y 1979), que vino a sustituir la Ley inicial de 1951 , y b) el «unitario regionalizado» italiano, con su Corte Costituzionale, desarrollada legislativamente en 1953 y posteriormente en 1962 y 1967, podemos señalar, en una perspectiva comparada, que las diferencias entre ambos modelos son casi irrelevantes.

1. Si bien podría considerarse un rasgo propio del sistema federal la dualidad de órdenes jurisdicciones constitucionales (el federal y el de los Laender) correlativo al dualismo de órdenes normativos jerarquizados respectivamente por la Ley Fundamental de Bonn y por las Constituciones de cada Land federado, tenemos, sin embargo, el hecho de que el Derecho federal prevalece sobre el de cada país en caso de conflicto, y así, un tribunal puede plantear cuestión de constitucionalidad si considera que la ley de un país federado contradice la Ley Fundamental federal ${ }^{23}$. Más aún: si el Tribunal Constitucional de un Land pretende separarse en su interpretación constitucional de la

${ }^{22}$ Obviamente no nos referiremos aquí a modelos de Estados unitarios, donde el control de constitucionalidad es mucho más dudoso que el italiano (bien por sus escasas modificaciones al sistema de «judicial review» - así, el colombiano que se remonta a 1910, o las referencias del artículo 26 de la Constitución irlandesa de 1937 a la cuestión de inconstitucionalidad, pero sin crear jurisdicción especial-, bien por seguir el modelo francés de control previo -muchas Constituciones del Africa francófona, singularmente las de Camerún y Senegal, ambas de 1960 -, bien por no haber logrado excesivo arraigo —cfr. artículos 145 a 152 de la Constitución turca de 1961, que seguía el modelo italiano de jurisdicción ad boc-; etc.).

${ }_{23}$ En el sistema federal alemán, cada uno de los Laender tiene su Tribunal Constitucional (Ländesverfassungsgericbt), que controla la constitucionalidad respectiva de la legislación de los Estados miembros. García de Enterría, cit., pág. 39, considera acertado, en cambio, haber configurado el modelo español sobre un único Tribunal Constitucional que concentra «el control de los sistemas jurídicos autonómicos, por relación tanto con los respectivos Estatutos como con la Constitución». Sin embargo, en nuestro actual régimen constitucional, los órganos superiores de las Comunidades Autónomas pueden iniciar un recurso directo sobre la constitucionalidad de las leyes, tanto propias como del Estado (y de otras Comunidades), lo cual aproxima la situación al dualismo territorial federal. 
decisión del Tribunal Constitucional federal (o del Tribunal Constitucional de otro Land), ha de solicitar el previo pronunciamiento del Bundesverfassungsgericht, con lo que la unificación jurisprudencial queda tan asegurada como en el sistema italiano.

2. Si en el sistema italiano el Tribunal Constitucional tiene el monopolio del control de constitucionalidad, también en la República Federal Alemana el Tribunal Constitucional decide con exclusividad en las cuestiones de Derecho constitucional federal.

3. Tampoco puede considerarse como rasgo específicamente federal el sistema concentrado o la vía principal según la inspiración kelseniana de la Constitución federal austríaca, puesto que esta vía coexiste en el régimen italiano (que no es federal) con la vía incidental o de excepción de inconstitucionalidad ${ }^{24}, y$, en cambio, es precisamente esta vía, según el modelo de control jurisdiccional difuso, la que caracteriza al pionero de los sistemas federales, el norteamericano.

4. La relación de dependencia en que se encuentra el poder judicial respecto al Bundesverfassungsgericht en el sistema constitucional de la República Federal Alemana no puede tampoco contraponerse estrictamente como rasgo característico federal frente al sistema italiano, puesto que éste se asemeja, en cambio, al federal austríaco en la independencia entre Tribunal Constitucional y tribunales ordinarios.

5. Aún más confuso sería utilizar como criterio diferenciador la tutela de los derechos públicos subjetivos, la cual es atribuida, ciertamente, en Italia (como en Francia, Portugal y otros Estados unitarios más o menos descentralizados) a los órganos judiciales ordinarios, y, en cambio, en Austria o la República Federal Alemana (en última instancia, puesto que el Tribunal Constitucional culmina el poder judicial) a la jurisdicción constitucional, ya que, además del carácter complejo de este último caso (más acentuado en el sistema mixto del federalismo suizo), podría señalarse, por el contrario, el caso de México, sin duda el país donde más arraigo y enriquecimiento jurídico conoce la institución del amparo, y que es precisamente un Estado federal donde la referida tutela se encomienda a la jurisdicción ordinaria.

6. Un discutido problema específico, que tampoco parece correlacionable con modelos territoriales de Estado, sino referible a las técnicas de la justicia administrativa, es el siguiente: en nuestro actual sistema de justicia constitucional, la articulación de los mecanismos de conflicto constitucional prevista entre el artículo 153 y el 161.2 de la Constitución de 1978, desarrollada por los títulos IV y V de la LOTC de 3 de octubre de 1979, otorga al Estado una doble panoplia de control respecto a las disposiciones autonómicas: por una parte, contra aquellas «con fuerza de ley» (153.a); por otra, respecto a las disposiciones y resoluciones de rango inferior $(161.2)^{25}$, mientras que las

24 Para Pizzorusso (DGCE-TC, I, pág. 279) es ésta, incluso, «la más importante» entre las : funciones de la Corte, con lo que la participación del juez ordinario a través de la cuestión de constitucionalidad se aleja del sistema concentrado.

${ }_{25}$ Por cierto que no deja de ser curioso que el salomónico plazo de cinco meses de suspensión a las disposiciones autonómicas impugnadas ante el Tribunal Constitucional (introducido finalmente en el artículo 161.2 por la Comisión Mixta Congreso-Senado) coincida ahora al parecer con el que se va a imponer transitoriamente a la LOAPA en sede parla- 
Comunidades Autónomas sólo disponen del primer tipo de recursos ${ }^{26}$. ¿No es evidente el alejamiento del modelo federal y el predominio del Estado central? Pues resulta que, en cambio, no se ha atribuido directamente al Estado (a diferencia del caso italiano y según el modelo federal alemán, creado sobre todo por la jurisprudencia) ${ }^{77}$ la posibilidad de veto suspensivo, quedando la impugnación sujeta a la garantía mediadora de la jurisdicción constitucional, la cual únicamente se referirá al carácter constitucional de dicho conflicto y no a su contenido administrativo.

7. Una diferencia notable entre los Estados federados y los Estados unitarios más o menos descentralizados se refiere a la territorialización de iure o de facto en la composición del órgano jurisdiccional de garantías constitucionales, sea éste un tribunal ad boc o bien el Tribunal Supremo o Federal ${ }^{28}$. Pero se ha atribuido perceptivamente «la no regulación de una presencia de criterios de representación territorial en la composición del Tribunal» al «tratamiento poco serio, huidizo y excesivamente coyuntural que nuestros constituyentes dieron al importante tema de las autonomías ${ }^{29}$, y que llegó a poner en peligro la atribución al Tribunal Constitucional de la competencia para resolver conflictos entre Estado y Comunidades Autónomas. La laguna de la LOTC respecto al «peligro de las tendencias centralistas en el seno de nuestro Tribunal Constitucional» ${ }^{30}$ podría salvarse, sin embargo, en el futuro por el establecimiento de una convención constitucional del tipo de la que inteligentemente ha propugnado el profesor Aguiló ${ }^{31}$. De todas maneras, esta función centralizadora restrictiva de las autonomías es clara en la historia de la Corte Costituzionale y también creciente (relacionada con el federalismo cooperativo) en el Tribunal de Karlsruhe.

mentaria, pero que parece, en cambio, escaso para un dictamen meditado sobre el problema También resulta llamativo que el «cuarto bloque competencial» (García de Enterría, op. cit., págs. 55-56) - junto a recursos y cuestiones de constitucionalidad, amparo y conflictos de competencia-, el "control previo de inconstitucionalidad" por nuestro Tribunal Constitucional, de discutida coherencia en nuestro tipo de jurisdicción constitucional, inspirado más bien en sistemas embrionarios como el Conseil Constitutionnel de la V República francesa -y en modelos aún más politizados de combinación de control previo con control concentrado, como son el chipriota y el portugués-, vaya ahora a emplearse precisamente para la aprobación de la LOAPA, uno de los frutos más evidentes del famoso dictamen de la Comisión de Expertos presidida por el prestigioso profesor de la Complutense.

${ }_{26}$ Véase la polémica entre García de Enterría, cit., pág. 53, y las posiciones de Rubio Llorente y Aragón, en «La jurisdicción constitucional», y Leguina, en «Las Comunidades Autónomas», ambos trabajos recogidos en el estudio dirigido por Predieri y el propio García de Enterría, La Constitución española de 1978, Madrid, Cívitas, 1980, págs. 885-886 y 826, respectivamente; asimismo, las observaciones críticas de Serrera, «Las . Comunidades Autónomas y las impugnaciones del artículo 161.2 de nuestra Constitución», en DGCE-TC, III, págs. 2523-2537.

${ }_{27}$ García de Enterría, cit., págs. 53-54, siguiendo a Stern.

${ }^{28}$ Como subrayan Bowie y Friedrich, Estudios sobre el federalismo (Buenos Aires, 1958, páginas 167 y sigs.) y, entre nosotros, L. Aguiló, «La presencia de las nacionalidades y regiones en el Tribunal Constitucional», DGCE-TC, I, págs. 357 y sigs.

${ }^{29}$ Idem, pág. 365, apoyándose también en la crítica de M. Aragón, «El control de constitucionalidad en la Constitución española de 1978», en Revista de Estudios Politicos, número 7 , cit., 1979 , págs. $184-185$.

${ }_{30}$ Como pone de relieve Vandelli (en De Vergotini, Una Costituzione democratica per la Spagna, Milán, F. Angelo, 1978), págs. 224-226.

${ }_{31}$ Aguiló, cit., pág. 367. 
8. De la misma maneta, la importante cuestión de la protección constitucional de las autonomías locales frente a la acción legislativa de los Laender, que, según el estudio pionero del profesor Martín Mateo, caracteriza al sistema federal alemán ${ }^{32}$, no es tampoco categóricamente diferenciable del reconocimiento constitucional que el Estado regional italiano asegura a la autonomía local ni del doble equilibrio que la Corte Costituzionale ha tenido que proteger en varias ocasiones entre Estado, regiones y enti territoriali minori, aunque en el caso italiano (al igual que el español y a diferencia del alemán) las corporaciones locales no están legitimidas para plantear recursos de inconstitucionalidad. Las sentencias del Tribunal Constitucional italiano han defendido a menudo la autonomía municipal y provincial frente a las mismas regiones, «si bien en todos estos casos lo que realmente se está postulando es la primacía del ordenamiento estatal sobre el regional en lo que a Administración local se refiere» ${ }^{33}$.

La enumeración de zonas en donde la diferenciación entre ambos modelos de mayor influencia en el diseño de nuestra jurisdicción constitucional aparece compleja e incluso borrosa podría sin duda alargarse y sobre todo depurarse, pero no pretendemos ir más lejos en esta aproximación inicial. En definitiva, la dificultad en este punto de delimitar claramente un modelo de control de la constitucionalidad propio del Estado federal y otro adecuado al tipo de Estado unitario más o menos descentralizado o regionalizado hay que relacionarlo probablemente con la crisis del viejo mito del federalismo como soberanía compartida y con la emergencia del llamado «federalismo cooperativo», al que ya hemos aludido (y que cuenta con importante bibliografía, así como con valedores entre nosotros de la talla de Lojendio, García de Enterría o Trujillo), modelo este último al que cabe asimilar, como se ha postulado en el epígrafe anterior, la dinámica de nuestros procesos autonómicos. El propio Tribunal Constitucional tendrá que aceptar, por tanto, que el «fantasma federal» ${ }^{34}$ seguirá estando con nosotros mientras nuestra organización territorial no se base en la generalidad y una relativa homogeneidad, lo cual no se refiere precisamente a la LOAPA, sino a la superación federal de la política del «agravio comparativo».

\section{SOBRE COMPETENCIAS Y CONCORDANCIAS}

Antes de entrar en un análisis somero de la jurisprudencia inicial sobre temas autonómicos conviene recordar que una de las cuestiones más vidriosas de la Constitución es el sistema de dos listas de competencias «exclusivas» de los artículos 148 y 149 , envuelto en una mítica nebulosa de monopolios territorialmente contrapuestos, aborrascada hoy además con el confuso y crispado debate en torno a la LOAPA, pero que, pese a todo, deja ya entrever un

32 Martín Mateo, El Municipio y el Estado en el Derecho alemán, Madrid, 1965, así como su reciente aportación «La Garantía Constitucional de las Autonomías Locales», en DGCE-TC, II, en especial, págs. 1624-1627. Corte.

${ }^{33}$ Martín Mateo, op. cit., 1981, pág. 1626, con referencias a concretas sentencias de la

${ }^{34}$ Solozábal, op. cit., págs. 53 y sigs. 
complejo y variado paisaje de competencias compartidas y concurrentes, parcialmente solucionable por las técnicas de las delegaciones y transferencias y de la ley-marco previstas en la Constitución, pero en cualquier caso con amplias «zonas competenciales comunes». Una sólida doctrina administrativa, encabezada por T. R. Fernández, Cosculluela, Muñoz Machado y un nutrido etcétera ha desmontado la supuesta «exclusividad» de la mayoría de competencias, abriendo una salida al laberinto propiciado por la confusa redacción del título VIII y especialmente de los artículos referidos, ya que se había caído en el absurdo de calificar como «exclusivas» competencias en realidad concurrentes sobre la misma materia, en que el Estado tiene la «exclusividad» de la legislación de bases y algunas Comunidades Autónomas la «exclusividad» de la legislación de desarrollo, diferenciables además de las competencias compartidas según ámbitos territoriales y de las competencias concurrentes en que puede distinguirse la «exclusividad» legislativa de la «exclusividad» ejecutiva. Son especialmente estas contradicciones las que están originando más conflictos reconducidos ante la jurisdicción constitucional.

Si bien es cierto que no debe abusarse de las analogías con el Derecho comparado, «pues cada sistema tiene su vida propia, genera su propia dinámica, y de él hay que partir para solucionar los problemas que se planteen", como ha señalado reciente y acertadamente el magistrado de nuestro Tribunal Constitucional profesor Gómez-Ferrer ${ }^{35}$, no debemos perder tampoco la capacidad de diagnosticar que aporta el acreditado método comparativo, que desde Aristóteles es el más fructífero para la más antigua de las ciencias sociales. No parece aventurado el diagnóstico sobre una dinámica enfermiza que puede, evidentemente, amenazar la «vida del sistema», como es el actual desbordamiento de conflictos de competencia y recursos de inconstitucionalidad con trasfondo autonómico, auténtica amenaza que puede bloquear el papel arbitral de nuestro Tribunal Constitucional.

Prescindiendo de cuestiones específicas como el muy discutido tratamiento jurídico del deslinde competencial en la LOTC y sus implicaciones procesales ${ }^{36}$, que no podemos abordar aquí, parece pertinente recordar la experiencia del Verfassungsgerichtshof austríaco, que prueba cómo en las zonas competenciales comunes es decisiva la interpretación del Tribunal Constitucional, y ello pese al principio de atribución residual (art. 15 de la Constitución austríaca) en favor de los Laender de las materias no expresamente transferidas por la Constitución a los poderes federales, cláusula reforzada además por la negativa kelseniana a formular un principio de supremacía de la ley federal sobre la ley del Land (a diferencia del caso alemán); el Tribunal austríaco ha ido, sin embargo, elaborando una jurisprudencia centralizadora utilizando sus funciones

${ }^{35}$ Prólogo a R. Bocanegra, El valor de las sentencias del Tribunal Constitucional, Madrid, IEAL, 1982, pág. xiii.

${ }_{36}$ El tema es abordado a fondo por el magistrado Domínguez Martín, el profesor Fernández Rodríguez - que pone magistralmente de relieve sus implicaciones políticasy otros autores de comunicaciones recogidas en los volúmenes citados de DGCE-TC: es evidente en todo caso que el «bloque de la constitucionalidad» definida por dicha ley orgánica se amplía más allá de los Estatutos y la Constitución hacia la realidad de un predominio de competencias efectivamente compartidas según leyes ordinarias, debiendo incluirse estas últimas, por tanto, en dicho «bloque» sometido al control de la jurisdicción constitucional. 
de interpretación constitucional ${ }^{37}$ (facilitadas desde luego tanto por la eficacia procesal que articula su Ley de 1953, con las importantes reformas de 1978, cuanto por la amplitud territorial que la reforma de 1946 dio al artículo 137, incluyendo expresamente a distritos, municipios y agrupaciones municipales entre los sujetos sometidos a control constitucional ${ }^{38}$ ).

En nuestra actual situación conviene recordar asimismo que, por ejemplo, ante el Bundesverfassungsgericbt de la República Federal Alemana no se han tramitado más de la docena de conflictos entre la Federación y los países federados (aunque algunos tuvieran gran importancia por la materia, como televisión o armamento atómico) y, en cambio, se acercan ya a los 2.000 los procedimientos de «control normativo concreto» ${ }^{39}$ (es decir, las cuestiones de inconstitucionalidad, según la terminología del artículo 163 de nuestra Constitución) ante el Tribunal Constitucional Federal. ¿Llegarán nuestros procesos de caos territorial y conservadurismo judicial a invertir las cifras para el caso español? De ello llevamos camino.

$\mathrm{La}$ experiencia combinada de los Tribunales Constitucionales federales austríaco y alemán parece indicar que el actual bloqueo de nuestra jurisdicción constitucional por los conflictos de competencia se deriva de una deficiente regulación de la materia en el título VIII de la Constitución. El miedo al «fantasma del federalismo», infundado, puesto que una jurisdicción constitucional, como demuestra el caso austríaco, puede racionalizar hasta el más laxo de los sistemas federales, ha desembocado en esta absurda situación. La doctrina ha señalado este hecho con rara unanimidad. De ahí que, si la raíz del problema es la deficiente técnica del título VIII, los «paños calientes» de Comisiones legitimadoras de pactos extraparlamentarios o de medidas tan confusas como la LOAPA, que más vienen a embrollar con su dudosa constitucionalidad que a «armonizar» los frutos lógicos de aquella raíz caótica, poco solucionarán eficazmente un tema que sólo mediante una adecuada reforma constitucional de la distribución territorial de competencias en el sentido del federalismo cooperativo podría afrontarse con la hondura que la cuestión requiere. Es evidente, sin embargo, que la reforma constitucional no está en el horizonte de las posibilidades políticas inmediatas, ni tampoco las fuerzas políticas que más pugnan por inscribir la cuestión de la reforma constitu-

${ }^{37}$ Schaeffer, Verfassungsinterpretation in Österreich, Viena, 1971, págs. 97-118, así como Walter, Österreichisches Verfassungsrecht, Viena, 1972, págs. 731 y sigs.; entre nosotros, E. Alonso García, «EI Tribunal Constitucional austríaco», en DGCE-TC, I, páginas 424-429. Esta labor del Tribunal austríaco como «guardián del principio federal», interpretado en el más actual sentido de «federalismo cooperativo», viene a subrayar las amplias posibilidades de incidencia jurisprudencial creadora en el tema de la distribución territorial de competencias.

${ }^{38}$ La sección quinta de la parte tercera, procesal, de la Ley de 1974, reguladora del Bundesverfassungsgericht alemán, se refiere también a los municipios y agrupaciones municipales como sujetos legitimados para acudir a la jurisdicción constitucional, en este caso mediante el amparo (o «queja» en la terminología alemana) cuando una ley contradiga el artículo 28.2 de la Ley Fundamental, que garantiza constitucionalmente la autonomía municipal.

${ }_{39}$ Véanse los datos referidos a 1977 que recoge el magistrado J. L. Manzanares en «El Tribunal Constitucional Federal Alemán», DGCE-TC, II, págs. 1560-1561; asimismo, el análisis y referencias bibliográficas que presenta F. Sainz, «El Tribunal Constitucional Federal Alemán», en Boletín de Jurisprudencia Constitucional, 8 (1981), págs. 601-624. 
cional en el orden del día de nuestra vida parlamentaria son precisamente todas favorables a fórmulas federales. Pero no parece de recibo tampoco el argumento de que el mero planteamiento de la urgencia de una reforma en esta materia sea desestabilizador «porque hace el juego a las fuerzas centralistas», ya que el axioma político que desde Burke sostiene que la mejor defensa de una Constitución es su reforma frecuente y paulatina está suficientemente probado, empezando por el modelo originario del federalismo que es la Constitución norteamericana de 1787.

Ahora bien: tampoco cabe ignorar las responsabilidades respectivas, descargando todas las culpas en nuestros constituyentes; cada palo ha de aguantar su vela, y mientras desde la doctrina no se plantee sistemáticamente este tema de la reforma federal del título VIII de la Constitución (lo que quizá sea más una condición que una consecuencia del posicionamiento al respecto de los partidos parlamentarios, dado que la irracional hostilidad a la fórmula federal por parte de la derecha española es uno de los obstáculos más serios para una salida consensuada al actual impasse), planteamiento que en todo caso deberá ser más técnico y de praktische Konkordanz que basado en ideologismos políticos, es indudable que el Tribunal Constitucional deberá continuar en su papel, hasta ahora tan brillantemente desempeñado que hasta la fórmula finalmente salvadora del espinoso proyecto de la LOAPA ha tenido que remitirse a su dictamen. Ante tal irrisión de los viejos dogmas de la soberanía parlamentaria, el papel de árbitro de la jurisdicción constitucional en los conflictos constitucionales entre Estado y Comunidades Autónomas podría, sin embargo, llegar a parecerse al de bombero. Este peligro se acentuaría caso de empecinarse un sector de la doctrina en prescindir de toda referencia federal y seguir en cambio como modelo preferente para encontrar una salida el italiano o regional, no obstante el desbordamiento de los supuestos «unitario-regionales» por nuestras «nacionalitarias» autonomías; no sería extraño que la difícil y conflictiva experiencia italiana de autoafirmación «horizontal» de la Corte Costituzionale entre los demás órganos constitucionales se vea amplísimamente superada por las batallas «verticales» entre los controles mutuos estato-comunitarios, amenazando con replantear el viejo dilema entre justicia politizada y judicialización de la política que Schmitt asociara a la crisis de la democracia.

\section{SOBRE LA EVOLUCION INICIAL DE NUESTRA JURISPRUDENCIA CONSTITUCIONAL EN MATERIA DE COMPETENCIAS TERRITORIALES}

Entre las incesantes providencias del Tribunal Constitucional que en las páginas del $B O E$ van marcando el ritmo de los enfrentamientos entre el Gobierno (y su presidente) y los órganos superiores de las Comunidades Autónomas ya constituidas (en especial con la Generalidad de Cataluña y el Gobierno vasco), y anticipando así los ámbitos de producción jurisprudencial de nuestro Tribunal Constitucional, van apareciendo ya, junto a numerosísimos conflictos positivos de competencia ${ }^{40}$, bastantes recursos de inconstituciona-

* El artículo 59 de la LOTC atribuye a éste el conocimiento de los diversos conflictos de competencia derivados del Estado autonómico (párrs. 1 y 2), considerados, por ejemplo, 
$\operatorname{lidad}^{41} \mathrm{e}$ incluso las primeras impugnaciones ${ }^{42}$ previstas en el artículo 161.2 de la Constitución y en el título V de la LOTC.

Próximos a cumplirse los dos años de funcionamiento del Tribunal Constitucional, aunque todavía sea prematura una cuantificación significativa (habrá que esperar a ver si los varios centenares de providencias registradas en 1981, por ejemplo, reflejan tendencias institucionales o expresan ciertos desequilibrios entre las fuerzas políticas, en el supuesto de que ambos factores puedan aislarse) ${ }^{43}$, es interesante observar la evolución inicial de su jurisprudencia, refiriéndola aquí a los ocho aspectos que en el epígrafe II, supra, analizamos como primera aproximación a la dificultad de definir algunas características comparadas de un modelo federal o bien regional de control de la constitucionalidad.

1. En lo que se refiere a la posible articulación entre órdenes normativos y órdenes jurisdiccionales ${ }^{44}$, encontramos una ortodoxa interpretación de las concordancias entre el título VI y el discutido artículo 152.1 de la Constitución en la STC de 14 de julio de 1981, que subraya que «el artículo 14 del Estatuto de Autonomía para el País Vasco se limita a fijar "la competencia de los órganos jurisdiccionales en el País Vasco'. Se habla de órganos jurisdiccionales en el País Vasco y no del País Vasco, con lo cual se indica por el propio Estatuto que las competencias de los órganos jurisdiccionales no son competencias de la Comunidad Autónoma», de forma que se va mucho más lejos que la propia Comisión de Expertos en el giro restrictivo hacia los futuros Tribunales Superiores de Justicia; en la argumentación del mismo fundamento

por el profesor Lucas Verdú («Política y justicia constitucionales. Consideraciones sobre la naturaleza y funciones del Tribunal Constitucional», DGCE-TC, II, págs. 1545-1546) como los conflictos constitucionales «de mayor carga política».

${ }_{41}$ El artículo 66 de la LOTC establece, en el ámbito de los conflictos entre Estado y Comunidades Autónomas, que «la sentencia declarará la titularidad de la competencia controvertida», aunque el artículo 67 admite en su caso la acumulación procedimental como «tecurso de inconstitucionalidad». La situación creada por la LOAPA hace perfectamente previsible un aumento en la utilización de estos procedimientos, puesto que los Estatutos de Autonomía, en cuanto leyes orgánicas, están amparadas por el recurso de inconstitucionalidad, según preceptúa el artículo 28.2 de la LOTC, pero también lo están las demás leyes orgánicas...

${ }_{42}$ Por ejemplo, del Gobierno contra la resolución del presidente de la Generalidad de Cataluña aprobando Convenio con el Consejo Regional de Murcia: providencia de 19 de mayo de 1982.

${ }_{43}$ Quizá sea ya, en cambio, más significativa la cuantificación en ámbitos que aquí no pueden abordarse; así, contrasta una relativa abundancia de recursos de amparo con la llamativa escasez de cuestiones de inconstitucionalidad. Por cierto que no se han computado aquí autos, muchos de ellos, sin embargo, importantes; en su mayoría se refieren a inadmisibilidad de recursos de amparo. En los seis primeros meses de funcionamiento del Tribunal se dictaron ya 116 autos: véase un primer estudio en Boletín de Jurisprudencia Constitucional, núm. 3, julio de 1981 .

${ }^{4} \mathrm{He}$ abordado este tema desde la óptica heterodoxa (por federalista) que aquí se ha propugnado, y con abundantes referencias del Derecho constitucional compatado, en mi ponencia «El principio de unidad jurisdiccional y los Tribunales Superiores de las Comunidades Autónomas», presentada a las Jornadas de Estudio sobre «El poder judicial» que aparecerán en 1983 publicadas por la Dirección General de lo Contencioso del Estado. $\mathrm{La}$ interpretación que en dicha ponencia se hace del artículo 152.1 y su congruencia con el artículo 117 es que la unidad jurisdiccional tiene su verdadero relieve en el ámbito de «unidad de fuero», tan escasamente boyante todavía entre nosotros pese a los mandatos constitucionales, y, en cambio, es susceptible de articulación tertitorialmente compleja. 
jurídico 6 de dicha sentencia, y además de apoyar el carácter no excepcional de la Audiencia Nacional, frente a la doctrina procesalista más consecuente, se insiste en que «la relación con la Comunidad Autónoma no es una relación orgánica, sino una relación territorial que deriva del lugar de su sede, y que las competencias de los órganos jurisdiccionales continúan siendo competencias del poder judicial único existente en el Estado». Como hemos señalado en otro lugar, esta interpretación del artículo 152.1 se aleja incluso de las propuestas más sensatas de presidentes de Audiencias Territoriales respecto a una descentralización del Consejo General del Poder Judicial relacionada con las Comunidades Autónomas ${ }^{45}$.

2. Respecto a la exclusividad del control de la constitucionalidad por el Tribunal Constitucional es vigorosamente confirmada por las STC de 2 de febrero de 1981, 1 de junio de 1981 y 31 de marzo de 1981. En la primera de las citadas se resuelve el alcance de las posibilidades judiciales de inaplicación de normas anteriores a la Constitución y contrarias a ésta (utilizando el mandato de la disposición derogatoria tercera), pero, en cambio, sometida a la cuestión de inconstitucionalidad (restrictivamente interpretada por STC de 1 de junio de 1981) para las leyes posteriores: «La cuestión de inconstitucionalidad no es una acción concedida para impugnar de modo directo y con carácter abstracto la validez de la ley, sino un instrumento puesto a disposición de los órganos judiciales para conciliar la doble obligación en que se encuentran de actuar sometidos a la ley y a la Constitución. La estricta aplicación del principio de jerarquía permitiría al juez resolver el dilema en que lo situaría la eventual contradicción entre la Constitución y la ley con la simple inaplicación de ésta, pero ello hubiera implicado someter la obra del legislador al criterio tal vez diverso de un elevado número de órganos judiciales, de donde podría resultar, entre otras cosas, un alto grado de inseguridad jurídica» (fundamento jurídico 1). Sólo el Tribunal Constitucional es, pues, en nuestro ordenamiento, «legislador negativo».

3. En cuanto a la compatibilidad entre las vías principal e incidental, aunque la acumulación prevista en el artículo 67 de la LOTC del conflicto de competencias con el recurso de inconstitucionalidad ${ }^{46}$ es procesalmente muy similar al procedimiento de inconstitucionalidad derivado de una cuestión planteada por órgano judicial (art. 37.2, en relación con el art. 34 de la LOTC: los órganos son prácticamente los mismos, Cámaras parlamentarias, Gobierno y en su caso órganos legislativo y ejecutivo de la Comunidad Autónoma, con muy ligeras variaciones de plazos), la referida escasez de cuestiones de inconstitucionalidad promovidas por jueces o tribunales se refleja también en este aspecto territorial; únicamente la citada STC de 1 de junio de 1981, en la medida en que se refiere a la Compilación del Derecho Civil Especial de Cataluña, adquiere importancia en este ámbito territorial; por cierto que el citado fundamento jurídico 1 expresa una actitud restrictiva al respecto: «La extraordinaria trascendencia de las cuestiones de inconstitucionalidad como princi-

${ }^{45}$ Véase en ibid. referencias a las propuestas de Rodríguez-Aguilera desarrolladas en «El poder judicial en las Comunidades Autónomas», Revista Jurídica de Cataluña, v. 80, núm. 3, 1981, págs. $777 \mathrm{y}$ sigs.

${ }^{46}$ Para una meridiana diferenciación entre el recurso de inconstitucionalidad y el conflicto positivo de competencias cf. STC de 28 de julio de 1981, fundamento jurídico 1. 
pal mecanismo de conexión entre la jurisdicción ordinaria y la constitucional obliga, sin embargo, a extremar las garantías destinadas a impedir que esta vía procesal resulte desvirtuada por un uso no acomodado a su naturaleza», si bien esta cautela se pronuncia tras haber sentado una jurisprudencia estimulante a la vía incidental: «La depuración continua del ordenamiento, desde el punto de vista de la constitucionalidad de las leyes, y siempre a salvo la acción del propio legislador, es así resultado de una colaboración necesaria entre los órganos del poder judicial y el Tribunal Constitucional, y sólo esta colaboración puede asegurar que esta labor depuradora sea eficaz y opere de manera dinámica y no puramente estática, ya que. sólo por esta vía, y no por la del recurso de inconstitucionalidad, cabe tomar en consideración el efecto que la cambiante realidad social opera sobre el contenido de las normas.»

4. La independencia y también la colaboración entre los tribunales ordinarios respecto al Tribunal Constitucional resulta, pues, subrayada por esta jurisprudencia inicial: junto a esta importante sentencia de 1 de junio de 1981, ha sido ya muy comentada la STC de 2 de febrero de 1981 (singularmente el voto particular del magistrado Rubio Llorente en lo referente a las competencias exclusivas y concurrentes del tribunal con los jueces ordinarios) ${ }^{47}$, y la de 31 de marzo de 1981, que reafirma la posible concurrencia de la depuración incidental y de la principal respecto al ordenamiento jurídico; en esta última sentencia se contempla la naturaleza del propio Tribunal: «... el Tribunal Constitucional, que no forma parte del poder judicial y está al margen de la organización de los Tribunales de Justicia, como la propia Constitución pone de manifiesto al regular en títulos diferentes unos y otros órganos constitucionales (el VI y el IX, respectivamente). Sin embargo, este Tribunal actúa, especialmente en los procesos de amparo, como tal Tribunal y con base en un procedimiento de carácter jurisdiccional, bien que regulado de manera espe-

47 El fundamento jurídico $1, d$, considera que el Tribunal Constitucional ostenta el monopolio para enjuiciar la conformidad con la Constitución de las leyes posteriores a ésta, pero que los jueces ordinarios, frente a leyes anteriores, pueden inaplicarlas por entenderlas contrarias a la Constitución, sin necesidad de acudir al Tribunal Constitucional, en base a la referida disposición derogatoria tercera. Esto no implica que el poder judicial enjuicie al poder legislativo, función exclusiva del Tribunal Constitucional, y la posibilidad de tal concurrencia de Tribunal Constitucional y Tribunales ordinarios respecto a leyes anteriores a la Constitución se basa en el valor erga omnes de la jurisprudencia constitucional. Sobre esta distribución competencial más similar al modelo italiano que al federal alemán, véase F. Llorente, «Notas sobre jurisprudencia constitucional», Revista La Ley, núm. 180, 1981, página 3. El voto particular del magistrado Rubio Llorente discrepa de esa concurrencia competencial entre Tribunal Constitucional y Tribunales ordinarios, atribuyendo a estos últimos la función exclusiva de fijación de la norma vigente y, por tanto, de la declaración de derogación respecto a leyes anteriores a la Constitución; el voto particular admite que el Tribunal Constitucional pueda rectificar interpretaciones judiciales de leyes anteriores a la Constitución a través del recurso de amparo y la cuestión de inconstitucionalidad, pero no a través de un recurso directo de inconstitucionalidad; esta misma tesis es razonada por M. Aragón en «La sentencia del Tribunal Constitucional sobre leyes relativas al régimen local anteriores a la Constitución», Revista Española de Derecho Constitucional, número 1, 1981, págs. 185 y sigs.; en cambio, se ha mostrado muy crítico de tal posición D. López Gartido, «Un año del Tribunal Constitucional: la fijación jurisprudencial de su función y competencias. El concepto de inconstitucionalidad sobrevenida», en esta misma revista, núm. 13, 1982, págs. 204-209. Sobre el concepto de «cosa juzgada» en el modelo federal alemán y su utilidad para precisat la función del Tribunal Constitucional, véase en general Bocanegra, op. cit. 
cial en su ley orgánica» (fund. jur. 1). Sobre este carácter jurisprudencial insisten el auto numero 107, de 26 de noviembre de 1980, o las STC de 8 de junio de 1981 (fund. jur. 1) o 18 de mayo de 1981, y, por otra parte, habría que considerar el número ya considerable, y con tendencia cuantitativamente creciente, de las sentencias del Tribunal Supremo que aplican directamente la Constitución desde $1979^{48}$.

5. La tutela de los derechos públicos subjetivos es ya el ámbito de más numerosa producción jurisprudencial ${ }^{49}$, a la que no podemos referirnos aquí; pero el hecho de que sólo durante 1981 se interpusieran ante el Alto Tribunal cerca de quinientos recursos por parte de ciudadanos disconformes con sentencias de jueces y tribunales, especialmente en materia de libertad, igualdad, derecho a la libertad sindical y a la educación, replantea con ciertos matices de urgencia el problema de las relaciones entre poder judicial y Tribunal Constitucional; es significativo que en estos procedimientos se reivindicara el derecho constitucional a protección jurisdiccional basado en el artículo 14 (véase STC de 29 de marzo de 1982) incluso frente a resoluciones judiciales (STC de 29 de enero de 1982, núm. 4).

6. La descomposición del carácter recíproco de los controles estato-comunitarios en favor de un más intenso control estatal se expresa, por ejemplo, en las STC de 14 de julio de 1981, 28 de enero de 1982 y 22 de febrero de 1982. Sin embargo, es importante la delimitación conceptual contenido en la primera de las citadas, número 2: «La protección de las Comunidades Autónomas frente a actos de los poderes centrales del Estado que ellas estimen contrarios a su interés propio pueden procurarse, en cuanto tal protección haya de buscarse ante este Tribunal, a través de dos vías específicas, la del conflicto de competencias y la del control de constitucionalidad, que son complemento la una de la otra. En términos generales hay conflicto de competencia cuando dos órganos se consideran igualmente competentes o incompetentes para proveer en un determinado asunto, y control de constitucionalidad de las normas cuando se comprueba la validez de una norma contrastándola con otra de nivel superior en los términos del artículo 28.1 de la LOTC, sin que se pretenda el ejercicio de la competencia normativa por parte del que impugna la validez» (fund. jur. 2). Veremos, sin embargo, que es el Estado, más que las Comunidades, quien se ha beneficiado de esta doble vía, lo que, a juicio del Tribunal, significa un mayor respeto al texto constitucional por parte de aquél ${ }^{50}$.

7. No hay jurisprudencia aún respecto a la cuestión (suscitada en la

4s Esta copiosa producción está siendo recogida, por ejemplo, en el Boletin de Jurisprudencia Constitucional, que revela, sin embargo, una diversidad cualitativa en la apertura a los valores constitucionales.

${ }^{4} \mathrm{El}$ referido Boletín comenta ya abundantes recursos de amparo, comenzando por la STC de 26 de enero de 1981, y siguiendo a un ritmo de unas tres sentencias importantes por mes. La naturaleza objetiva de los derechos fundamentales, con independencia de la estructura territorial del Estado, es reafirmada por STC de 14 de julio de 1981, núm. 5 , en el recurso del Parlamento vasco contra la Ley Orgánica 11/1980, de 1 de diciembre.

${ }_{30}$ Sobre las conexiones entre los ámbitos de autonomía respectivos y la legitimación para recurrir son también significativas las STC de 14 de julio de 1981, núms. 2 y 3; de 28 de enero de 1982 (que acumula dos conflictos de competencia y expresa ya la inflexión más sensible a las pretensiones autonómicas tras la jurisprudencia inicial marcadamente centralizadora), y de 22 de febrero de 1982 (que asimismo acumula dos conflictos de competencia, pero que vuelve a la línea «unitaria»). 
doctrina y en el Derecho comparado, como indicamos) de la territorialización en la composición del propio Tribunal, si bien la referida STC de 14 de julio de 1981 revela una cierta hostilidad hacia el tema en relación con las pretensiones del Parlamento vasco de una cierta territorialización de desarrollo y protección judicial de los derechos fundamentales y las libertades públicas, consideradas por el Alto Tribunal incongruentes.

8. En cambio, el tema de las autonomías locales ha recibido ya una cualificada atención en la jurisdicción constitucional, pronunciándose en su favor tanto en la muy comentada sentencia de 2 de febrero de 1981 como en las STC de 29 de abril de 1981 y especialmente de 28 de julio de 1981 contra la Ley de Cataluña de 17 de diciembre de 1980 , que transfería las Diputaciones provinciales a la Generalidad. El fundamento jurídico 3 de la primera de las sentencias establece toda una teoría de la compatibilidad entre la «unidad de la nación española» y el control mediante «una distribución vertical de poderes». En el mismo número 3 de la última de las sentencias citadas se profundiza en esta «distribución vertical del poder público entre entidades de distinto nivel», que, por cierto, se asemeja notablemente a la teorización célebre de Loewenstein sobre el federalismo.

9. En realidad, el ámbito que aquí nos interesa, donde exiște ya más copiosa jurisprudencia constitucional (tanta que requeriría un estudio específico que esta primera aproximación, cuyo objeto es acotar áreas de estudio comparativo, no puede acometer), es el aludido en el epígrage anterior, de la delimitación concordante de competencias estato-comunitarias, con una dinámica analogable a la del «federalismo cooperativo»: la resultante de esta jurisprudencia implica prima facie una lectura bastante restrictiva del título VIII de la Constitución (así, STC de 13 de febrero de 1981, sobre competencias educativas; de 14 de julio de 1981, ya referida respecto a garantías jurisdiccionales de derechos fundamentales; de 28 de julio de 1981, especialmente restrictiva en la citada negativa a la asunción por la Comunidad Autónoma catalana de competencias provinciales; de 12 y 16 de noviembre de 1981, sobre privilegios de los parlamentarios autonómicos y competencias en materia de transporte, respectivamente; de 22 de diciembre de 1981, sobre competencias en materia de bibliotecas; de 8 de febrero de 1982, sobre la función pública; de 22 de febrero de 1982, sobre competencias educativas, y de 23 de marzo de 1982; sobre competencias en materia de radio y televisión).

Sin embargo, esta tendencia inicialmente predominante recibe una significativa inflexión mediado ya el segundo año de funcionamiento del Tribunal; bien es verdad que en varias de las sentencias referidas (así, en las de 13 de febrero de 1981, en la de 14 de julio de 1981 o en la de 16 de noviembre de 1981) hay cuatro importantes votos particulares, notoriamente suscritos por los mismos magistrados, que anuncian esa posible inflexión en sentido menos centralizador, puesto que la disidencia de hoy es a menudo la jurisprudencia de mañana, esas «verdades prematuras» que exaltara Lamartine. Pero es en la STC de 18 de diciembre de 1981, sobre designación de senadores representantes de Euskadi (desestimando el recurso promovido por el presidente del Gobierno contra la Ley del Parlamento Vasco 4/1981, de 18 de marzo), donde aparece ya una concepción más amplia de la «autonomía política», admitiendo una diversidad en la aplicación constitucional de la misma que repercute incluso 
en la composición del Senado; esta línea interpretativa continúa en las STC de 28 de enero de 1982, sobre competencias en materia de crédito (con una inclinación un tanto salomónica en cuanto al petitum, actitud eminentemente arbitral que se reafirma en la STC de 4 de mayo de 1982, sobre competencias en materia de legislación laboral, que, por cierto, establece en su número 1 meridiana jurisprudencia sobre el régimen de competencias concurrentes, tan mal delimitado por los artículos 148 y 149 del texto constitucional), o en la importante de 24 de mayo de 1982, que reconoce competencias autonómicas en materia de radiodifusión con modulación de frecuencia (y asimismo sienta fundamental jurisprudencia sobre competencias compartidas). Las recientes sentencias de 8 de junio de 1982 (en materia de sanidad y protección al consumidor) y de 14 de junio de 1982 (sobre competencia en materia de legislación laboral, siendo especialmente instructivo el número 2 respecto a las técnicas de articulación entre competencias estatales y autonómicas) confirman la expuesta evolución jurisprudencial; más favorable a las competencias autonómicas, pero con resultantes «salomónicas» en los fallos, tan híbridas como la propia delimitación de ámbitos competenciales comunes en el texto constitucional.

\section{CONCLUSIONES}

El anterior análisis, aun con su carácter introductorio y más bien sintético, que no de estudio pormenorizado de la jurisprudencia, indica una función especialmente intensa del Tribunal Constitucional en la delimitación competencial estato-comunitaria, como era previsible a la vista de la Constitución de 1978, casi tan vigorosa como la función tutelar de los derechos fundamentales que caracteriza primordialmente a la mayor parte de las jurisdicciones constitucionales. La escasez de cuestiones de inconstitucionalidad perfila esta inicial evolución del Tribunal Constitucional como un modelo escasamente mixto y muy acusadamente de carácter «concentrado», de vía principal en su control de la constitucionalidad.

$\mathrm{La}$ inicial línea de interpretación en el ámbito de las competencias territoriales, acusadamente centralizadora (con el matiz de las disidencias reiteradas) y asimilable a la concepción regionalizada del modelo italiano, se ha variado posteriormente partiendo del referido principio federante de la distribución territorial como control vertical del poder. Una primera explicación global, con independencia de los méritos concretos de cada caso, es que la línea inicial, pese a sus importantes aportaciones técnicas respecto al régimen concurrencial de competencias, no tendía a disminuir los conflictos, sino a aumentarlos.

Por ello, y de acuerdo con la función arbitral del Alto Tribunal, se ha tendido a evitar la posible disfuncionalidad de dicha orientación interpretativa en la constatada inflexión registrable desde fines de 1981 y que parece confirmarse, acompañada probablemente de un perfeccionamiento técnico en la interpretación constitucional y estatutaria que aplican las Comunidades ya constituidas.

En cuanto al sentido que aquí se ha ofrecido insistentemente de una perspectiva federante a la interpretación constitucional no se basa en extranjeri-. 
zantes razones de Derecho comparado, sino que implica sobre todo la conciencia de que la teoría y la praxis de la interpretación constitucional convergen hoy en admitir que una Constitución no es nunca algo cerrado, sino una tarea abierta, «como algo a hacer a partir del caso» ${ }^{51}$. El razonamiento jurídico creativo no se opone así a la normatividad de la Constitución, sino que, a través precisamente de la acción jurisprudencial del Tribunal Constitucional, la asegura y vivifica.

Una última e inevitable reflexión ha de referirse a las consecuencias de la LOAPA sobre esta evolución inicial del Tribunal Constitucional, cuando éste empezaba a sentar su orden en este difícil ámbito: el peligro de que el Tribunal quede literalmente inundado de recursos gubernamentales contra la legislación y la acción administrativa autonómicas $-\mathrm{y}$, por tanto, semiparalizado- es ya inmediato. Las frecuentes salvas de recursos de inconstitucionalidad contra las normas autonómicas que fuerzan la interpretación constitucional pueden verse pronto ampliamente superadas por descargas continuas de recursos y por el tronar constante de los conflictos de competencia si ciertas instituciones autonómicas deciden basarse únicamente en la Constitución y sus respectivos Estatutos de Autonomía e ignorar la LOAPA ${ }^{52}$. En tal caso, el propósito de ésta de fijar claramente la primacía constitucional de las leyes del Estado sobre las normas autonómicas quedaría condicionado a la acción del Tribunal Constitucional, el cual, sin embargo, podría resultar inutilizado prácticamente ante un auténtico colapso de recursos y conflictos de competencias. No es posible extenderse aquí sobre esta cuestión decisiva ${ }^{53}$, pero tampoco cabe silenciarla, pues de la resolución de la misma por el propio Tribunal Constitucional puede depender nada menos que el equilibrio de nuestro régimen constitucional.

51 De Otto, «La posición del Tribunal Constitucional a partir de la doctrina de la interpretación constitucional», DGCE-TC, III, pág. 1949. El brillante planteamiento del profesor De Otto tiende, sin embargo, precisamente a oponerse a esta tendencia a la «indeterminación de la norma» en nombre de «una teoría de la Constitución que sirva de base a líneas orientadoras de la interpretación y a la elaboración de una dogmática constitucional (ibid., pág. 1950). El profesor Garrorena ( «La sentencia constitucional», en el núm. 11 de esta misma revista, 1981, págs. 7 y sigs.), aun subrayando especialmente la dimensión procesal, reconoce que la «esencia del tema» es la dimensión decisoria («actos de neto indirizzo político) que, junto a la integradora, constituyen, a juicio del profesor de Murcia, la «triple dimensión de la sentencia constitucional».

${ }_{52}$ Así lo han anunciado ya el Gobierno y el Parlamento vasco: cfr. El País de 7 de junio de 1982, en relación con la Asamblea de Zarauz del Partido Nacionalista Vasco.

${ }_{53}$ No obstante las mejoras realizadas en el proceso legislativo (que han limado, especialmente en el art. $4-\mathrm{y}$ pendiente su paso a sede senatorial-, sus aspectos más conflictivos con el propio texto constitucional), es grave el freno que esta Ley pueda suponer a la actividad legislativa de las Comunidades Autónomas, legítima desde los puntos de vista constitucional y estatutario, pero indudablemente difícil de compatibilizar a menudo con una legislación general «de bases» por parte del Estado, que no siempre cumple sus lógicas prioridades cronológicas; este problema lo ha tratado de resolver el Tribunal Constitucional como típica cuestión de competencias compartidas en la construcción del Estado autonómico. Especialmente conflictivo setía el bloqueo de la consolidación de las Administraciones autonómicas (que parecía, en cambio, uno de los aciertos del proyecto de LOAPA, aunque hubiera podido resolverse por una ley ordinaria específica racionalizadora de las transferencias de servicios y funcionarios del Estado a las Comunidades Autónomas). Los profesores Trujillo, Leguina y otros han manifestado ya sus reservas a esta modificación encubierta y centralizadora del título VIII de la Constitución y de los Estatutos de Autonomía aprobados; pero el tema merece estudiarse en tiempo y forma. 